\title{
Performance evaluation of locally developed black light trap for maize insects monitoring in Chitwan, Nepal
}

\author{
Ghanashyam Bhandari ${ }^{* 1}$, Shiva Kumar Jha ${ }^{1}$, Yagya Prasad Giri ${ }^{2}$, Hira Kaji \\ Manandhar ${ }^{3}$, Pramod Kumar Jha ${ }^{4}$, Nabaraj Devkota ${ }^{3}$, Praseed Thapa ${ }^{3}$ and \\ Resham Bahadur Thapa ${ }^{3}$ \\ ${ }^{1}$ National Maize Research Program, Chitwan, Nepal \\ ${ }^{2}$ Nepal Agricultural Research Council, Kathmandu, Nepal \\ ${ }^{3}$ Agriculture and Forestry University, Chitwan, Nepal \\ ${ }^{4}$ Tribhuvan University, Kritipur, Kathmandu \\ *Corresponding author email: bhandarigb_1978@yahoo.com \\ *ORCID ID: https://orcid.org/0000-0003-3705-3424
}

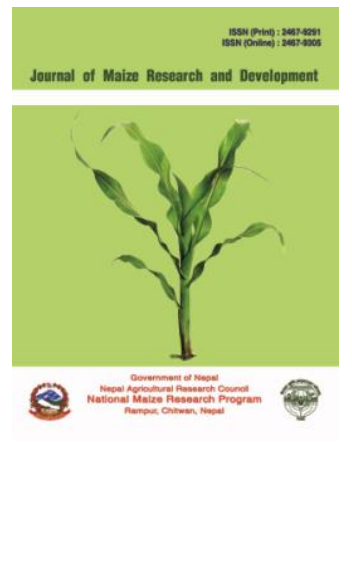

Received: November 01, 2017; Revised: November 15, 2017; Accepted: December 26, 2017

(C) Copyright 2017 Bhandari et al .

(c) (1) (8)

This work is licensed

under a Creative Commons Attribution-NonCommercial 4.0 International License.

\begin{abstract}
Till today, the light traps in Nepal are found using with traditional type, which have not being recognized internationally. These light traps were of low efficiency for trapping insects as compared to black light trap (BLT). The black light tube (F10T8/BL) was used in newly constructed trap at National Maize Research Program (NMRP), Rampur, Chitwan, Nepal. Both traps were installed at the maize experimental field at NMRP during February to October, 2017. Data on insect numbers were recorded once in a week from dusk to down in two different days to minimize the light effects of each others. The total number of insects trapped in BLT was 2804 as compared to 868 in traditional light trap (TLT). Among the insect orders, Coleopterans were mostly trapped in BLT followed by Lepidopteron and Hemipterans. The results showed that the trapping efficiency of BLT was three fold higher than that of TLT. Therefore, black light trap was highly effective monitoring tool and its field applications are expected to be commercialized.
\end{abstract}

Keywords: Light trap design, Insects attraction, Diversity, Coleoptera, Temperature

Correct Citation: Bhandari, G.S., Jha, S. K., Giri, Y.P., Manandhar, H. K., Jha, P. K., Devkota, N., Thapa, P., \& Thapa, R. B. (2017). Performance evaluation of locally developed black light trap for maize insects monitoring in Chitwan, Nepal. Journal of Maize Research and Development, 3 (1), 98-107. doi: http://dx.doi.org/10.3126/jmrd.v3i1.18926 


\section{INTRODUCTION}

Due to their high ecological diversification and short generation times, insects are useful indicators of environmental change (Thomas, 2005). Light trap is one of the very effective tools for monitoring and management of the insect pests as it mass-traps both the sexes of insect pests and also substantially reduces the carryover pest population. The most widely applied method to survey insects is to use light traps, which exploit their attraction to artificial light (Franzén \& Johannesson, 2007). Light traps are also used to determine seasonal patterns of insects' density in the cropped areas. It also provides information related to insect distribution, abundance, flight patterns and helps to decide the timing of the application of management tools (Singh \& Bambawale, 2012). There are number of types of light traps designed on the basis of different types of light mechanism. Typically, used lights are standard filament bulbs, mercury vapour bulbs, and fluorescent actinic tubes (Fry \& Waring, 2001). The trapping mechanism in the light traps can be designed in various ways which affects trapping performance (Intachat \& Woiwod, 1999). Three major factors must be considered in the design of any light trap: the first is an efficient light source, the second is an efficient apparatus for confining the specimens, and the third is an appropriate reception chamber with poison distributing mechanism for killing specimens and retaining them in good condition until they can be recovered for sorting (Hardwick, 1968). At the same time, a range of abiotic factors, such as temperature, rainfall, wind speed, moonlight, and cloud cover, need to be recorded at trap events to correct for their effects on insect flight activity and trap efficiency (Yela \& Holyoak, 1997; Beck et al., 2011). Among different types of light trap, the black light trap (BLT) is used for collecting many insects that are active and flying at night and are attracted to UV light. They have consistently caught a higher abundance and greater variety of insects than other traps (Muirhead-Thomson 1991; Neupane, 1982). Their key feature is the low-wavelength light attractant, which lures a diversity of flying insects from the surrounding habitat. Attracting nocturnal insects with ultraviolet light is now in general use and presents the most effective collecting method for nocturnal species of the orders Coleoptera, Othoptera, Lepidoptera, but also for many species of Hymenoptera, Diptera, Neuroptera (Sotthibandhu \& Baker, 1979). Different light sources that attract nocturnal insects, emit relatively large amounts of UV radiation (blue fluorescent lights, black lights, and mercury lamps) exert the strongest attraction (Aoki \& Kuramitsu 2007; Cowan \& Gries 2009). Pennsylvania insect light trap was initially used by the writer as a standard for comparison with other traps and was found outstanding (Frost, 1957). These traps were used for a variety of purposes, ranging from investigations in biodiversity, to pest monitoring, to taxonomic collections and for surveying a wide range of insect taxa (Baker 1985, Beck \& Linsenmair 2006). In traditional light trap, a mercury vapour bulb (125-400 W) is used that requires relatively high current to maintain the arc consuming more electric power and thus are limited in its use which has been recovered by using BLT. Since, such BLT has not compared with the conventional trap; this study will shows significant value in monitoring different insects and will provide the reference to the researcher towards using the impacts of such light traps. Thus, the objective of this study was to construct efficient, standardized and cheapest black light trap based on the principle of Pennsylvania light trap, using locally available materials which was evaluated with traditional trap on the basis of insect trapping capacity. 
MATERIALS AND METHODS

\section{Construction features of black light trap}

The materials used in Pennsylvania light trap in USA are not available in Nepal thus, locally available low cost materials such as fiber for baffle, wood for tube holder frame, galvanized iron sheet for top cover, funnel and collection chambers and iron angle for support frame. The shape and size of the light trap was modified accordingly keeping basic principle of Pennsylvania light trap. The black light tube (F10T8/BL) used in the model was of 10 watt, emitting $350 \mathrm{~nm} \mathrm{UV}$ rays. The length of the tube was $33 \mathrm{~cm}(\phi 3 \mathrm{~cm})$ which was fitted on the locally available plastic holders in vertical position and electrical connection was made with proper welding of 10 watt electrical chock. The holders were fitted on wooden base frame (Fig 1), which was tightened with the baffles. Four numbers of baffles $(41 \mathrm{~cm}$ long and $12 \mathrm{~cm}$ wide and $3.5 \mathrm{~mm}$ thick) made of fiber was framed on funnel at one end and top cover at another end (Fig 2). The dimensions of the rain shelter at top, the funnel, the insect collection chamber and iron stand are shown below in table 1 . A $60^{\circ}$ conical funnel having $28.5 \mathrm{~cm}$ and $5 \mathrm{~cm}$ in diameter at top and neck of the funnel respectively was bolted on the iron angled frame. The insect collection chamber has hanging mechanism on the funnel neck and based on the quick removal iron plate connected to the iron angled frame. The whole trap (Fig 3) has been fixed on the ground such that the lower portion of the light tube installed at a height of $1.5 \mathrm{~m}$. Traditional light trap using $125 \mathrm{~W}$ bulb was compared to evaluate the efficacy of two traps.

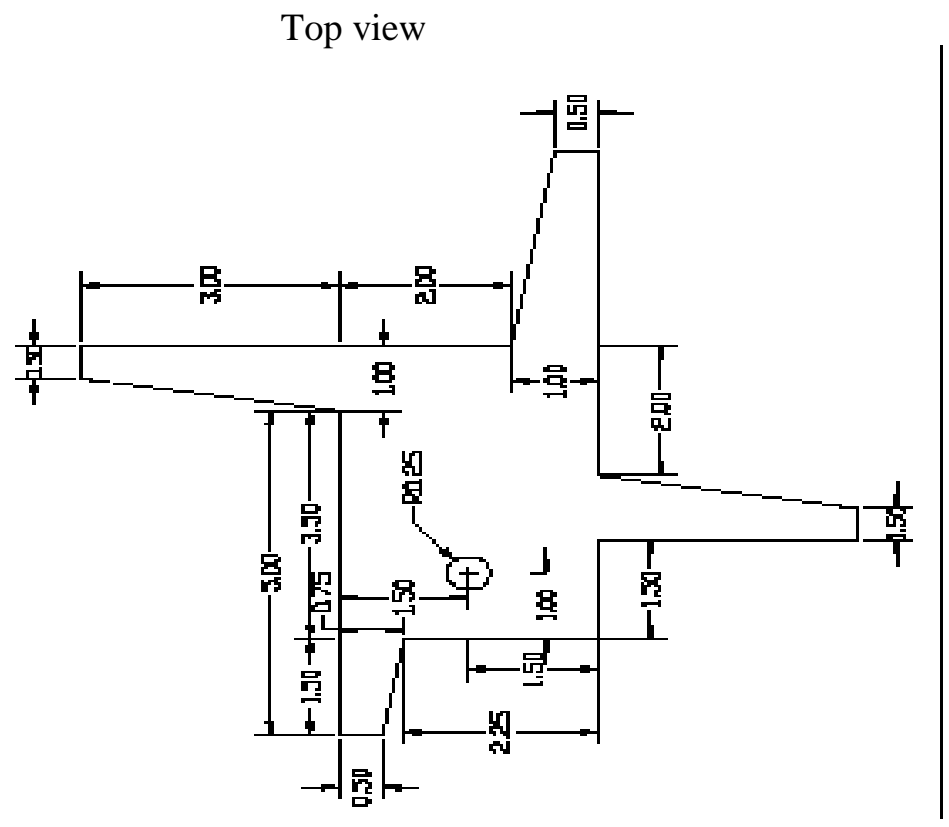

Side view

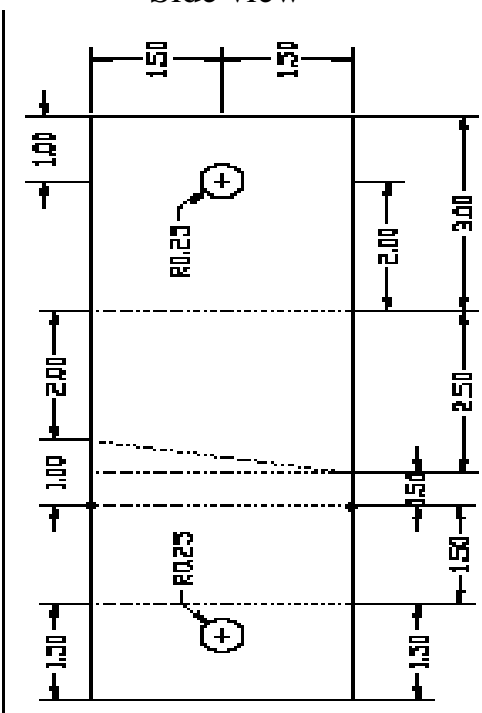

Fig. 1. Wooden base frame for tube holder 


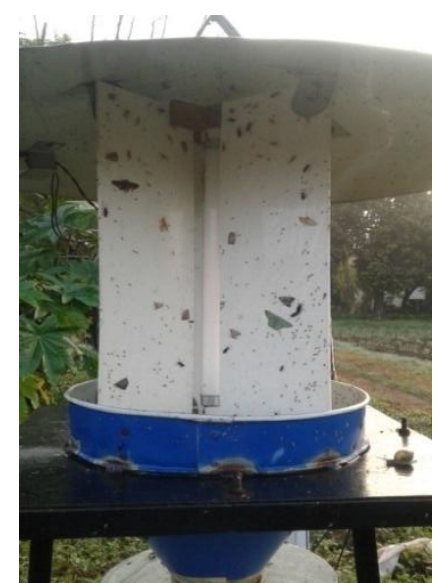

Fig. 2. Baffle fitted with funnel and top cover
DOI: http://dx.doi.org/10.3126/jmrd.v3i1.18926

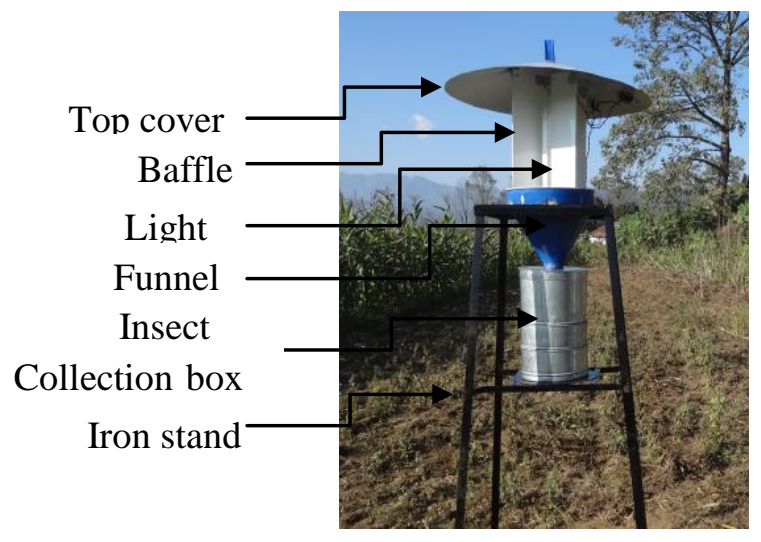

Fig. 3. Installed black light trap (BLT)

\section{Working mechanism of light trap}

As mention in the introduction section, the insects attracted due to emitted black light which strike on smooth white baffles surface and hence slide down in the insect collection chambers through funnel. Once the insects fall in the upper collection chamber, the sorting occur when the insects try to fly and find the opening for exit because of different dimensions of sieves at the bottom of each chambers (Fig 4). The sieve dimension of collecting chambers was chosen accordingly to categorize large, medium and small sized insects. This kind of shorting avoids damaging of wings, legs or antennae of insects, which helps identification of specimens. The collected specimens were killed using few drop of poison (ethyl acetate or carbon tetra chloride) in cotton which was kept inside each air tight collection chamber for few minutes.

\section{Data collection}

Both traditional and newly constructed black light trap (BLT) were placed in an open maize cropping area at experimental plots of NMRP, Rampur (latitude $27^{\circ} 40$ ' N, longitude $84^{\circ} 19^{\prime} \mathrm{E}$ and altitude $228 \mathrm{~m}$ above $\mathrm{msl}$ ) from February to October, 2017. The measurements were conducted once in a week from dusk to down in the fixed days. The traditional and black light trap were operated in two different days to minimize the light effects of each others. The collected insects were identified upto family level along with their taxonomic hierarchy and biological status to evaluate the performance of both traps.
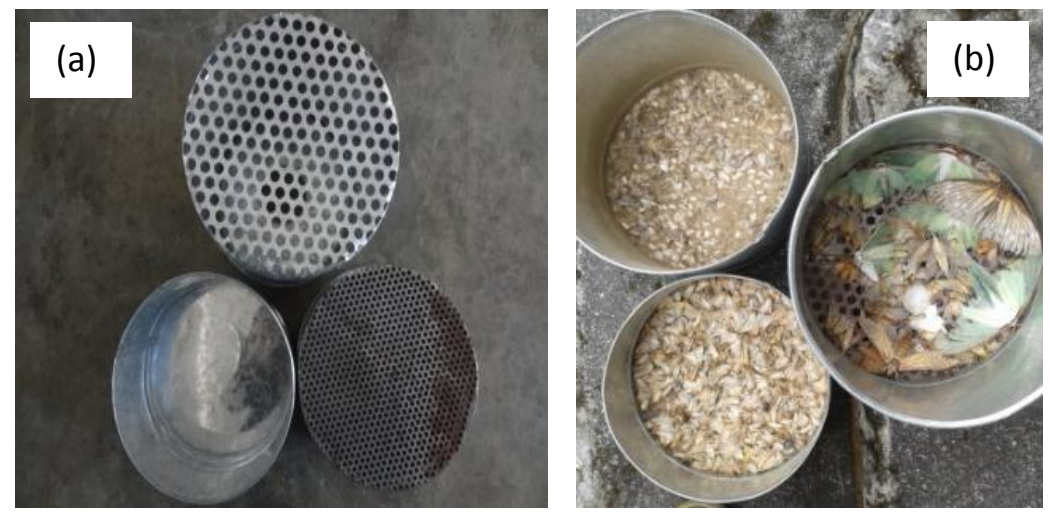

Fig. 4. Insect collection chamber (a) sieve at bottom of collection chamber (b) insects sorting in different chambers 
Table 1. Construction features of black light trap (BLT)

DOI: http://dx.doi.org/10.3126/jmrd.v3i1.18926

\begin{tabular}{|c|c|c|}
\hline Part of BLT & Dimension & Specification \\
\hline Black light tube & Length $33 \mathrm{~cm} ; \phi 3 \mathrm{~cm}$ & $\begin{array}{l}\text { F10T8/BL; Emits } 350 \quad \eta \mathrm{m} \\
\text { wavelength }(\lambda)\end{array}$ \\
\hline Rain shelter (at top) & $\phi 65 \mathrm{~cm}$ & GI sheet (20 gauge) \\
\hline Baffle & Length $41 \mathrm{~cm}$; width $12 \mathrm{~cm}$ and thickness $3.5 \mathrm{~mm}$ & Fibers sheet \\
\hline Conical funnel & Inclination $60^{\circ} ; \phi 28.5 \mathrm{~cm}$ (at top); $\phi 5 \mathrm{~cm}$ (at neck) & GI sheet (20 gauge) \\
\hline Iron stand & $\begin{array}{l}\text { Vertical height } 160 \mathrm{~cm} \text {; Base plate for funnel } 40 \\
\mathrm{~cm} \times 40 \mathrm{~cm} \text { (at top); foot straggle } 65 \mathrm{~cm} \text { x } 65 \mathrm{~cm} \\
\text { (at bottom) }\end{array}$ & Iron angle \\
\hline \multirow{3}{*}{$\begin{array}{l}\text { Insect collection } \\
\text { chamber }\end{array}$} & Top chamber (height $20 \mathrm{~cm} ; \phi 30 \mathrm{~cm}$ with led) & \multirow[t]{3}{*}{ GI sheet (20 gauge) } \\
\hline & Middle chamber (height $10 \mathrm{~cm} ; \phi 30 \mathrm{~cm}$ ) & \\
\hline & Bottom pan (height $20 \mathrm{~cm} ; \phi 30 \mathrm{~cm}$ ) & \\
\hline $\begin{array}{l}\text { Base plate for } \\
\text { collection chamber }\end{array}$ & Size $50 \mathrm{~cm}$ x $50 \mathrm{~cm}$; Position $68 \mathrm{~cm}$ from top plate & $\begin{array}{l}\text { Iron plate; quick removal } \\
\text { mechanism }\end{array}$ \\
\hline Sieve mesh & $\begin{array}{l}\text { Mesh } \phi 8 \mathrm{~mm} \text { (for top sieve); mesh } \phi 5 \mathrm{~mm} \text { for } \\
\text { (middle sieve) }\end{array}$ & GI sheet \\
\hline $\begin{array}{l}\text { Wooden base frame for } \\
\text { tube holder }\end{array}$ & Dimension as shown in fig. 1. & Wood \\
\hline
\end{tabular}

\section{Weather parameters}

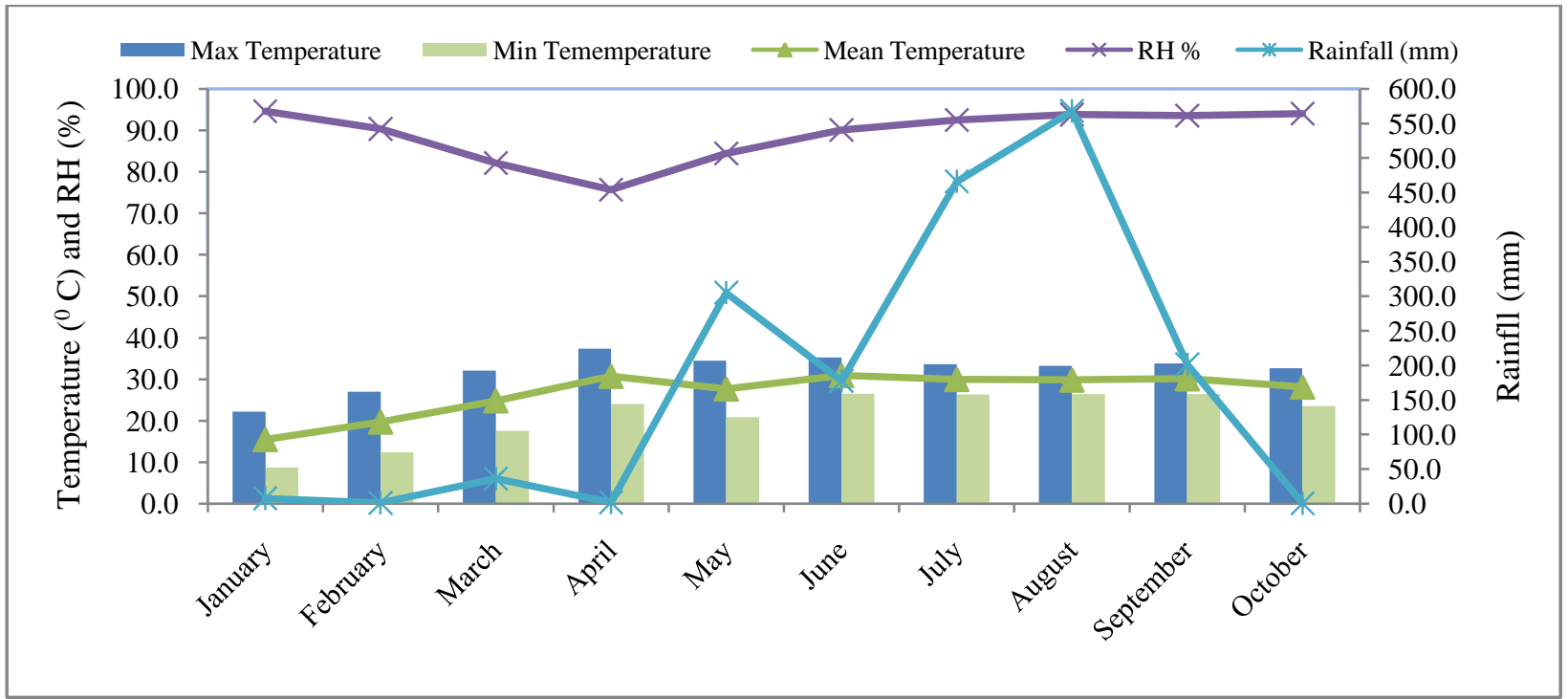

Figure 5: Weather parameters during experiment month of January to October, 2017 at NMRP, Rampur, Chitwan

\section{RESULTS AND DISCUSSION}

\section{Insect numbers}

Total number of insect catches was found higher in BLT as compared to TLP while monitoring at an interval of 15 days (Fig 6). The highest number (312) was trapped in mid August followed by end of April (295) and end of May (267). This result was similar to the result reported by Muirhead-Thomson (1991) that the BLTs had consistently caught a higher abundance and greater variety of insects during mid April to mid August than other traps. Similar results by (Mellanby, 1939; Holyoak, et al., 1997) showed that the higher insects were trapped from mid- 
Journal of Maize Research and Development (2017) 3 (1): 98-107

ISSN: 2467-9291 (Print), 2467-9305 (Online)

DOI: http://dx.doi.org/10.3126/jmrd.v3i1.18926

May to the end of August. This may be because the higher temperature (Fig 5) increases flight activity and the numbers present in an area of both species and individuals.

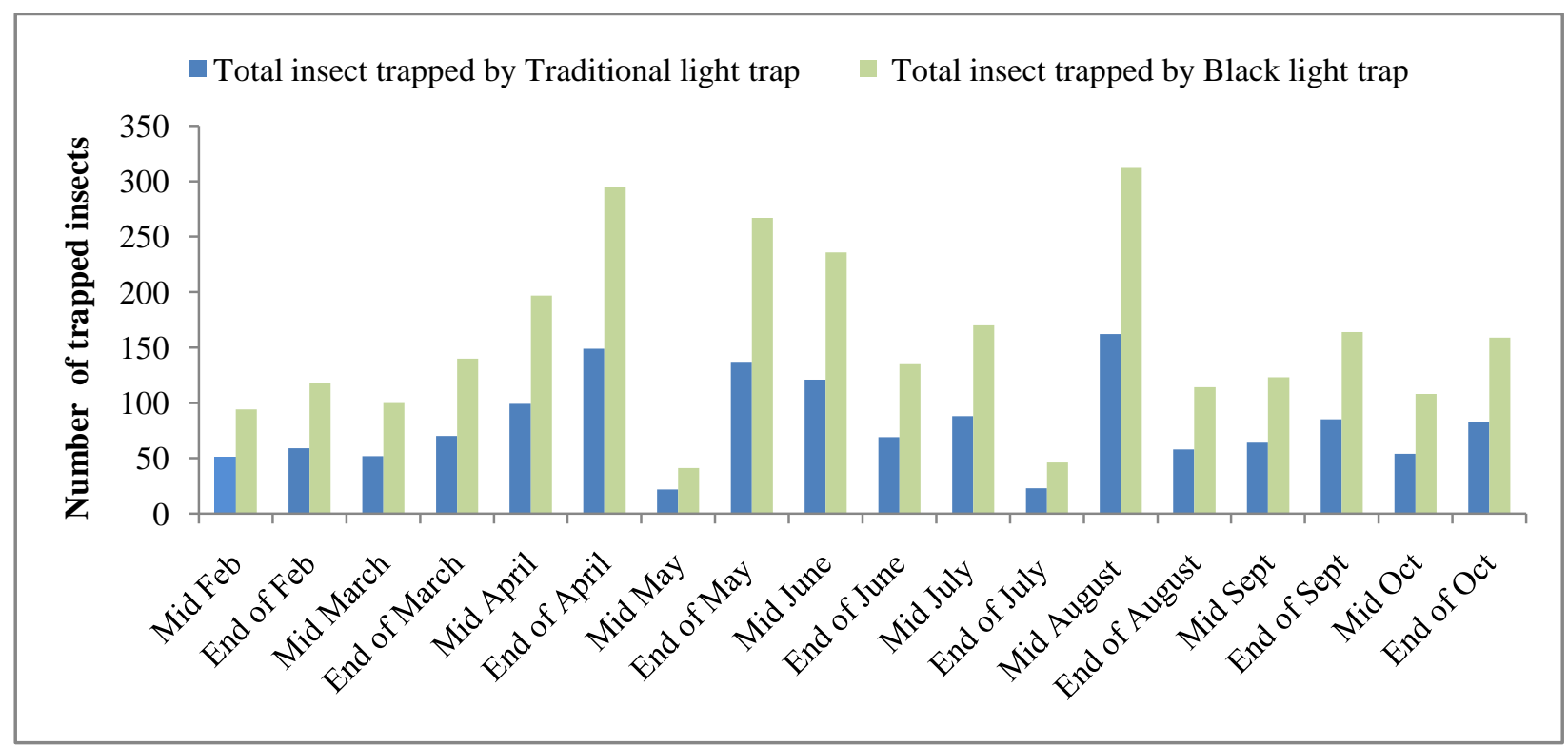

Fig. 6 Proportion of insect species with a peak in abundance in each month at NMRP, Rampur, Chitwan, Nepal, 2017

\section{Insect species}

The total number of insect species trapped was found higher in BLT than in TLP (Table 2). Among the trapped insect species in BLT, the highest number of white grub adults (1251) was caught followed by hairy caterpillars (512) and maize stem borers (297) monitored for 8 months from February to October, 2017.

Table 2 Number of insect species trapped at NMRP, Chitwan, during, 2017

\begin{tabular}{lcccc}
\hline \multirow{2}{*}{ Insect category } & \multicolumn{4}{c}{ Insect numbers } \\
\cline { 2 - 5 } & \multicolumn{2}{c}{ Traditional light trap } & Black light trap \\
\cline { 2 - 5 } & Adult (No) & Percent & Adult (No) & Percent \\
\hline Maize stem borers & 67 & 7.72 & 297 & 10.59 \\
White grubs & 252 & 29.03 & 1251 & 44.61 \\
Field crickets & 82 & 9.45 & 253 & 9.02 \\
Armyworms & 24 & 2.76 & 73 & 2.60 \\
Leaf folders & 50 & 5.76 & 118 & 4.21 \\
Red ants & 82 & 9.45 & 245 & 8.74 \\
Cutworms & 38 & 4.38 & 55 & 1.96 \\
Hairy caterpillars & 273 & 31.45 & 512 & 18.26 \\
\hline Total & $\mathbf{8 6 8}$ & $\mathbf{1 0 0}$ & $\mathbf{2 8 0 4}$ & $\mathbf{1 0 0}$ \\
\hline
\end{tabular}


DOI: http://dx.doi.org/10.3126/jmrd.v3i1.18926

Similar performance was suggested by Kalleshwaraswamy et al. (2016) who collected 131 adults during the trapping period of 30 June -15 October 2013 using light trap. Likewise, Dadmal \& Khadakkar (2014) reported that in total 19 species of scarab beetles belonging to 10 genera were the prominent visitors of BLT. The highest number of adult insects trapped in case of black light trap was chaffer beetle $(405=66.83 \%)$, where as it was only $22(3.36 \%)$ from an ordinary light trap (Thapa, 2007).

\section{Total order and families}

Among various insects collected in the traps, the major contributors were Coleopterans, followed by Lepidopterans, Hemipterans, Orthopterans, Dipterans and Hymenopterans. The result showed that the highest number of catches per family falls under Coleoptera followed by Lepidoptera and Hemiptra respectively (Fig. 7). Dadmal and Khadakkar (2014) observations revealed that Coleopterans followed by Hemipterans and Lepidopterans were the dominating orders caught. Similarly, (Ashfaq et al., 2005) observed the highest number of insects in container placed under the black light (UV light) and the lowest under red light trap.

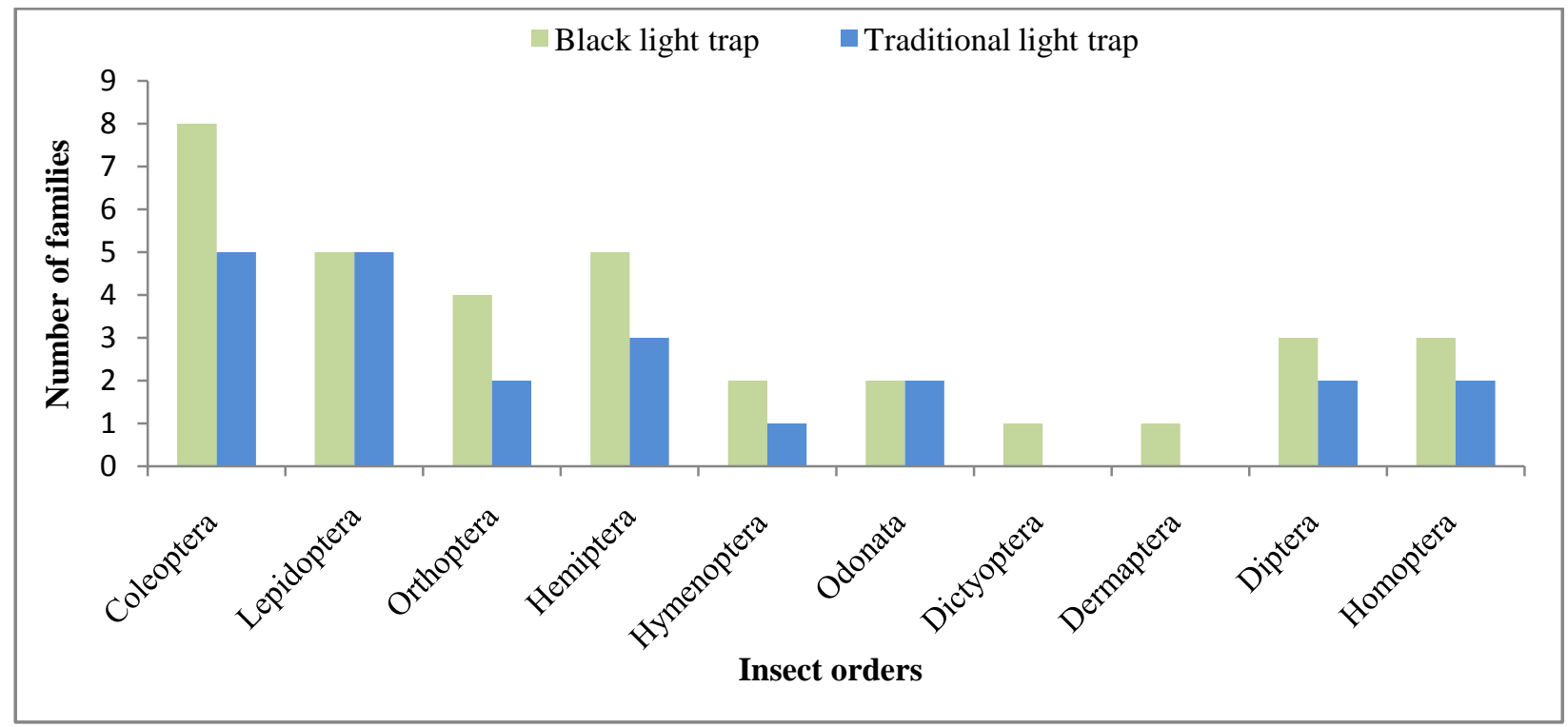

Fig. 7 Insect orders and families trapped through different light traps at NMRP, Chitwan during 2017

\section{Detail cost estimation of black light trap}

The detail estimate of all the parts of black light trap is presented in table 3 . The cost of all the materials used is as actual rate of local market price in 2016. 
Table 3 Estimated cost of black light trap (BLT)

\begin{tabular}{lccll}
\hline \multicolumn{1}{c}{ Items } & Quantity & Unit & Specification & Cost (NRs.) \\
\hline Rain shelter, funnel & 1 & No & GI sheet (20 gauge) & 2000.00 \\
Baffles & 4 & No & Fibers sheet & 2150.00 \\
Iron Frame & 1 & Set & Iron rod & 4000.00 \\
Base frame for tube holder & 2 & No & Wood & 500.00 \\
Black light tube & 1 & No & F10T8/BL (350 mn wavelength) & 2000.00 \\
$\begin{array}{l}\text { Electric wire, Chock, two pin, } \\
\text { holder, screw etc all complete }\end{array}$ & 1 & Set & 22/7 mm wire, chock-10 watt, plastic & 500.00 \\
Insect collection chamber with & 1 & Set & GI sheet & 2000.00 \\
led & 2 & No & GI sheet & 800.00 \\
Sieve & & & & 500.00 \\
Fitting charge & & & & 550.00 \\
Miscellaneous & & & & $\mathbf{1 5 0 0 0 . 0 0}$ \\
\hline Total cost & & &
\end{tabular}

\section{CONCLUSION}

Many drawbacks of TLPs have recovered through this study on BLT. The absence of striking and sieving mechanism in TLP has been fulfilled in BLT which helps for catching and instant sorting of trapped insects there by facilitating easy identification of specimens. The insect attracting capacity of BLT (350 $\eta \mathrm{m}$ wavelength; visible light) was found significantly higher than that of TLP. In same environmental condition and same interval of time, BLT has trapped large number of insect species, families and orders. It is of international standard, durable, portable and having wide range of insects trapping capacity from different habitats. Thus, it can be concluded that monitoring of insect species with BLT can provide thorough knowledge of the insect arthropod composition of an agro-ecosystem, there by identification of pest species, their economic level to start a management strategy. However, further evaluations of BLT in regard to the effect of altitude, crop height, information requirement and subsequent trap designs are required before its commercial branding.

\section{ACKNOWLEDGEMENTS}

This work was financially supported by the United States Agency for International Development (USAID) and the Future Innovation Lab for the Integrated Pest management (IPM), through a grant awarded for the "Participatory Biodiversity and Climate Change Assessment for Integrated Pest Management in the Chitwan Annapurna Landscape, Nepal" project. The authors are thankful to Dr Muni Rangappan (Virginia Tech ,USA), NMRP (NARC) and team of Agriculture and Forestry University for encouragement and advice. The research is free of bias.

\section{AUTHOR CONTRIBUTIONS}

G.S.B. designed and performed experiments, analyzed data and wrote the paper; S.K.J. designed the light trap; R.B.T., H.K.M., Y.P.G., N.D., P.K.J. and P.T. revised the article for final approval of the version to be published.

\section{CONFLICT OF INTEREST}

The authors declare that there is no conflict of interest. 


\section{REFERENCES}

Aoki, S., \& Kuramitsu, O. (2007). Development of insect-attracting lighting fixture and evaluation of insect attractiveness by a new index. J Illum Engng Inst Jpn, 91, 195-198.

Ashfaq, M., Khan, R. A., Khan, M. A., Rasheed, F., \& Hafeez, S. (2005). Insect orientation to various color lights in the agricultural biomes of Faisalabad. Pak. Entomol, 27(1), 49-52.

Baker, R. R. (1985). Moths: population estimates, light-traps and migration. Case studies in population biology. Manchester Univ. Press, Manchester, 188-211.

Beck, J. \& Linsenmair, K. E. (2006). Feasibility of light-trapping in community research on moths: attraction radius of light, completeness of samples, nightly flight times and seasonality of Southeast-Asian hawkmoths (Lepidoptera: Sphingidae). J. Res. Lepidoptera 39: $18-37$.

Beck, J., Brehm, G., \& Fiedler, K. (2011). Links between the environment, abundance and diversity of Andean moths. Biotropica, 43, 208-217.

Cowan, T., \& Gries, G. (2009). Ultraviolet and violet light: attractive orientation cues for the Indian meal moth, Plodia interpunctella. Entomologia Experimental iset Applicata, 131(2), 148-158.

Dadmal, S. M., \& Khadakkar, S. (2014). Insect faunal diversity collected through light trap at Akola vicinity of Maharashtra with reference to Scarabaeidae of Coleoptera. Journal of Entomology and Zoology Studies, 2(3), 44-48.

Franzén, M., \& Johannesson, M. (2007). Predicting extinction risk of butterflies and moths (Macrolepidoptera) from distribution patterns and species characteristics. Journal of Insect Conservation, 11(4), 367-390.

Frost, S. W. (1957). The Pennsylvania Insect Light Trap. Journal of Economic Entomology, 50(3).

Fry, R., \& Waring, P. (2001). A Guide to Moth Traps and Their Use, 2nd edn. The Amateur Entomologists' Society, Orpington, UK.

Hardwick, D. F. (1968). A brief review of the principles of light trap design with a description of an efficient trap for collecting noctuid moths. J. Lepid. Soc, 22(2), 65-75.

Holyoak, M., Jarosik, V., \& Novak, I. (1997). Weather-induced changes in moth activity bias measurement of long-term population dynamics from light trap samples. Entomologia Experimentalis et Applicata, 83(3), 329-335.

Intachat, J., \& Woiwod, I. P. (1999). Trap design for monitoring moth biodiversity in tropical rainforests. Bulletin of Entomological Research, 89(2), 153-163.

Kalleshwaraswamy, C. M., Adarsha, S. K., \&Naveena, N. L. (2016). Adult emergence pattern and utilization of females as attractants for trapping males of white grubs, Leucopholis lepidophora (Coleoptera: Scarabaeidae), infesting areca nut in India. Journal of Asia-Pacific Entomology, 19(1), 15-22.

Mellanby, K. (1939). Low temperature and insect activity. Proceedings of the Royal Society of London. Series B, Biological Sciences, 473-487.

Muirhead-Thomson, R. C. (1991). Plant pest responses to visual and olfactory 'sticky'traps. Trap Responses of Flying Insects. Academic Press Ltd, London, UK.

Neupane, F.P. (1985).The Bionomics of the Maize Borer, Chilopartellus (Swinhoe) in Nepal. Ph.D. Thesis, Departement of Entomology, University of Wisconsion-Madison, Winsconsion, USA. Pp 200. 
Saini, R. K., \& Yadav, P. R. (2007). Sampling, surveillance and forecasting of pests. Entomology: Novel Approaches, 19.

Singh, S. K. \& Bambawale, O. (2012). Light trap for managing insects. Indian Council of Agricultural Research, Unit Natinal Center For Integrated Pest Management. http://www.google.com/patents/WO2012098484A1?cl=en

Sotthibandhu, S., \& Baker, R. R. (1979). Celestial orientation by the large yellow underwing moth, Noctuapronuba L. Animal Behaviour, 27, 786-800.

Thapa, R. B. (2007). Monitoring insect population through light trap at the institute of Agriculture and Animal Science, Rampur, Chitwan, Nepal. IAAS Res. Adv. 1:141-145.

Thomas, J. A. (2005). Monitoring change in the abundance and distribution of insects using butterflies and other indicator groups. Philosophical Transactions of the Royal Society of London B: Biological Sciences, 360(1454), 339-357.

Yela, J. L., \& Holyoak, M. (1997). Effects of moonlight and meteorological factors on light and bait trap catches of noctuid moths (Lepidoptera: Noctuidae). Environmental Entomology, 26(6), 1283-1290. 